\title{
CD133-positive cancer stem cells from colo205 human colon adenocarcinoma cell line show resistance to chemotherapy and display a specific metabolomic profile
}

\author{
Zangiacomi Vincent ${ }^{1}$, Kenichi Urakami ${ }^{2}$, Koji Maruyama ${ }^{3}$, Ken Yamaguchi ${ }^{1}$, \\ Masatoshi Kusuhara ${ }^{1}$ \\ 1. Regional Resources Division, Shizuoka Cancer Center Research Institute, Shizuoka, Japan \\ 2. Cancer Diagnostics Research Division, Shizuoka Cancer Center Research Institute, Shizuoka, Japan \\ 3. Experimental Animal Facility, Shizuoka Cancer Center Research Institute, Shizuoka, Japan \\ Correspondence to: Masatoshi Kusuhara, email: m.kusuhara@scchr.jp \\ Keywords: cancer stem cells, CD133, metabolomics, adenocarcinoma, CE-TOF-MS \\ Received: June 16, $2014 \quad$ Accepted: July 25, 2014 \\ Published: July 27, 2014
}

This is an open-access article distributed under the terms of the Creative Commons Attribution License, which permits unrestricted use, distribution, and reproduction in any medium, provided the original author and source are credited.

\section{ABSTRACT:}

During the past decade, cancer stem-like cells (CSCs) have drawn substantial interest in cancer research since they have been described as major targets to improve treatment of tumors and to prevent recurrence and metastasis. In this paper, we report on the search for CSCs within the Colo205 human adenocarcinoma cell line. We describe that CD133 (prominin) was the only reliable marker for the isolation and characterization of CSCs within a Colo205 cell population. CD133-positive cells displayed many CSC characteristics, such as tumorsphere formation ability, expression of early-stage development markers, high invasiveness, raised tumor initiation potential and resistance to cisplatin chemotherapy treatment. In vitro analyses also highlighted a specific metabolomic profile of CD133-positive cells and we concluded that the chemotherapy resistance of CSCs could be related to the quiescence of such cells associated with their reduced metabolism. Furthermore, in vivo metabolome analyses suggested that a high level of circulating glutathione molecules could also promote treatment resistance. From the perspective of metabolomics, we also discuss the controversial use of serum-free in vitro cultures for CSC enrichment prior to further phenotype characterization.

\section{INTRODUCTION}

It is now well established that cancer stem-like cells (CSCs) can be identified within in vivo tumor bulks or in vitro cell cultures thanks to several markers $[1,2,3]$. Many studies have already reported the presence of CSCs in different solid tumors, such as breast, brain, prostate, lung, ovary, colon, pancreas, liver, melanoma, head and neck $[4,5,6,7]$. The most common membrane markers used for the sorting or analysis of CSCs are CD133, CD44 and aldehyde dehydrogenase (ALDH1), while many other specific markers have also been described, such as CD24 and epithelial-specific antigen [3, 4, 8, 9, 10]. Nevertheless expression of these markers is highly heterogeneous, depending on cancer localization, cell type and the tumor microenvironment.
CD133 (prominin) is a membrane glycoprotein that was first described on hematopoietic and neural stem/ progenitor cells. CD133 protein was later reported as a marker of poor prognosis within cancers (e.g. colorectal/ breast cancer and myeloid leukemia) and was subsequently confirmed as being specifically expressed by the CSC population $[3,11,12,13,14]$. Another molecule, CD44, is expressed by a large number of mammalian cell types. This protein was first discovered on human hematopoietic stem cells and then identified in several cancers $[4,9]$. Some studies also revealed that ALDH1, another common marker used for CSC identification, was also intimately correlated with tumorigenesis $[1,8,15,16]$.

Several studies have already reported the presence of CSCs within colon cancers; they were described as a rare population characterized by self-renewal capacity, 
clonogenicity, multipotency and chemoresistance $[3,5$, $10,17]$. The scarcity of CSCs within cancer unfortunately impedes their detection and isolation. However, it has been well established that serum-free cultures can lead to in vitro stem cell enrichment through tumorsphere formation $[6,14]$.

Our study focused on the analysis of metabolome using capillary electrophoresis time-of-flight mass spectrometry (CE-TOF-MS). We characterized and quantified over 100 intracellular metabolites involved in human metabolic pathways. Several metabolomic approaches in cancer research have been reported yet [18, $19,20,21]$ and many proteomic applications for analyzing urine or serum of patients have also been conducted, confirming the high resolution and sensitivity of such techniques for clinical diagnoses [22, 23].

In this study, we highlighted that CD133 is the only reliable marker for CSC characterization within the Colo205 colon adenocarcinoma cell line. Besides, metabolome profiles further revealed that the serumfree expansion protocol commonly used for in vitro proliferation of progenitors may create too many artifacts in cell metabolism, reducing the efficacy of such a method prior to phenotype analyses or sorting.

\section{RESULTS}

\section{Colon adenocarcinoma cell lines can form tumorspheres in vitro.}

We compared the in vitro culture of cells in a basal condition (10\% FBS) and in a serum-free condition. The cultures revealed that the Colo205 cell line could give rise to tumorspheres in serum-free conditions only. In contrast, cultures under FBS conditions only led to a layer of adherent confluent cells (Figure 1A). To rule out the possibility that cells may aggregate due to culture at a high concentration of cells, only 100 cells were seeded in each well. Tumorspheres could also be observed under these conditions. These results confirmed that tumorsphere-like colonies could be obtained from the Colo205 cell line and expanded in serum-free medium supplemented with EGF and bFGF, even under conditions with an extra-low cell concentration.

\section{In vitro characterization of Colo205 cell line.}

As in vitro serum-free conditions could lead to floating cell enrichment and colonies, we decided to analyze the phenotype further. mRNA expression levels in Colo205 tumorspheres were not significantly different from those under basal conditions (FBS 10\%), even after five weeks of culture, with regard to the expression of early-development CD133, hTERT and ABCG-2 mRNA (Figure 1B). Nevertheless, immunofluorescence and cytometry analyses showed an evolution of phenotype when cells were exposed to serum-free medium. The analyses confirmed the loss of early and late differentiation markers such as nestin and cytokeratin 20 (CK20), while the expression of embryonic and stem cell markers such as oct $3 / 4$ and CD133 was increased in non-serum cultures (by two and five times, respectively, compared with the control) (Figures 1C, 2A, 2B).

\section{CD133+ Colo205 cells exhibit CSC characteristics.}

To assess the stem-cell profile of different cell fractions, we further performed cell selection on the Colo205 cell line. RT-PCR analyses revealed that Colo205 $\mathrm{CD} 133+$ purified cells exhibited significantly increased expression of early-development mRNAs such as CD133, ABCG-2, hTERT, oct4, nanog and nestin $(\mathrm{p}<0.05)$ compared with basal Colo205 cells (neg.) (Figure 1B). We
$1 \mathrm{~A}$

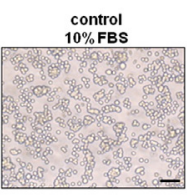

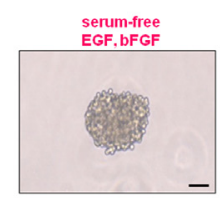
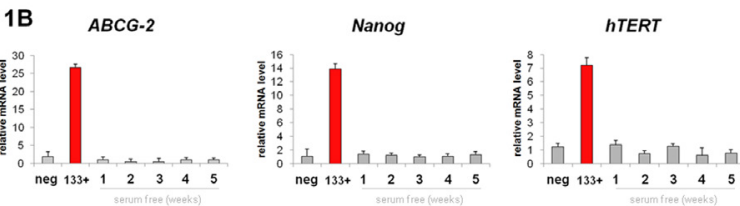

$1 \mathrm{C}$

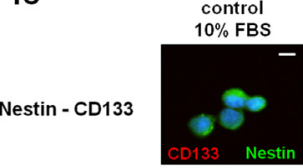

CK20 - CD133
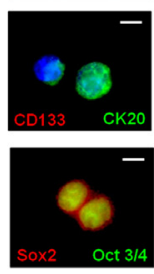

Oct 3/4 - Sox 2
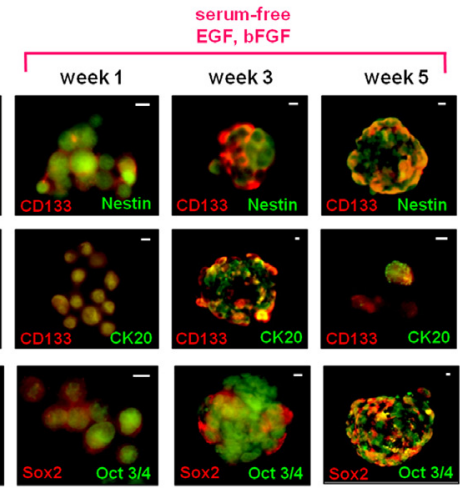

Figure 1: Serum-free cultures enrich Colo205 cells in CSCs. A. Colo205 cells cultured in 10\% FBS or serum-free conditions. Scale bar $=50 \mu \mathrm{m}$. B. Relative expression of ABCG2, nanog and hTERT mRNA of Colo205 cells grown under $10 \%$ FBS conditions (control), CD133+ sorted cells and serum-free growing cells (week 1 to week 5). C. Immunofluorescence analyses of nestin, CD133, CK20 and Oct $3 / 4$ proteins. Images show 10\% FBS Colo205 growing cells (control) and serum-free growing cultures (week 1 to week 5). Scale bar $=5 \mu \mathrm{m}$. 
also investigated the colony formation of both CD133+ and CD133- sorted cells from the Colo205 cell line in soft agar. Our results showed that colony formation efficiency levels for CD133+ and CD133- cells were $42.2 \pm 2.3 \%$ and $11.3 \pm 3.1 \%$ respectively, indicating that the CD133+ population displayed high clonogenicity compared with the resulting CD133- fraction (Figure 3A).

\section{CD133+ population from Colo205 is enriched in ALDH1-positive cells.}

We investigated the presence of the ALDH1 marker on Colo205 cells after CD133 selection. Quantification was then performed by cytometry analyses. The results revealed that $1.7 \pm 0.2 \%$ of $C D 133+$ cells co-expressed the ALDH1 molecule, while $0.2 \pm 0.1 \%$ of CD133- cells did. The Colo205 CD133+ cell population was thus shown to be enriched in terms of ALDH1-expressing cells.

2A Nestin

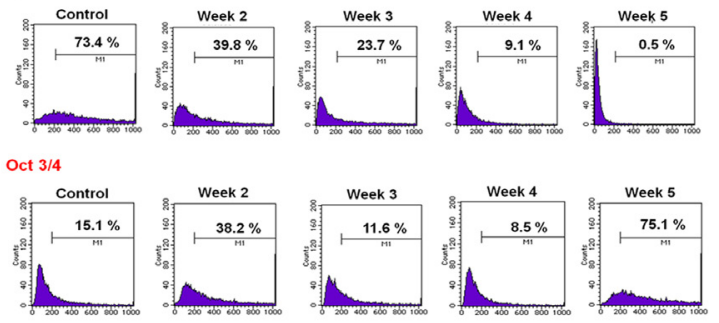

2B
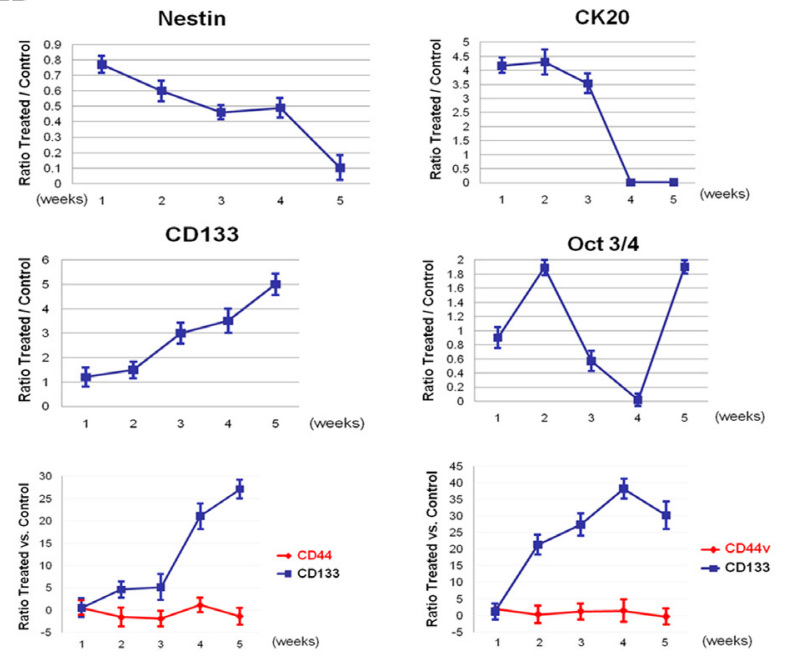

Figure 2: Serum-free cultures lead to the loss of early and late development markers and increase of stemlike markers. A-B. Cytometry analyses of Nestin, CK20, CD133, Oct3/4, CD44 and CD44v9 on 10\% FBS Colo205 growing cells (control) and serum-free growing cultures (week 1 to week 5).

\section{CD133+ subpopulation displays increased invasiveness.}

In vitro invasion assays were performed on several Colo205 sorted subpopulations using a collagen-based cell invasion method. The results showed that the CD133+ purified population was significantly more invasive than the CD133- resulting fraction or the control fraction (absorbance units $(\mathrm{AU})=0.99,0.15$ and 0.27 , respectively; $\mathrm{P}<0.01)$. No significant difference was observed for both CD44+ and CD44- fractions (AU=0.30 and 0.26, respectively) (Figure $3 \mathrm{~B}$ ). These results confirmed that Colo205 CD133+ cells exhibited greater tumorigenic capacity than the CD133- and CD44+/- cells.

\section{CD133+ cells are resistant to cisplatin chemotherapy.}

To assess drug sensitivity, chemotherapy survival assays were performed after CD133 and CD44 selection.
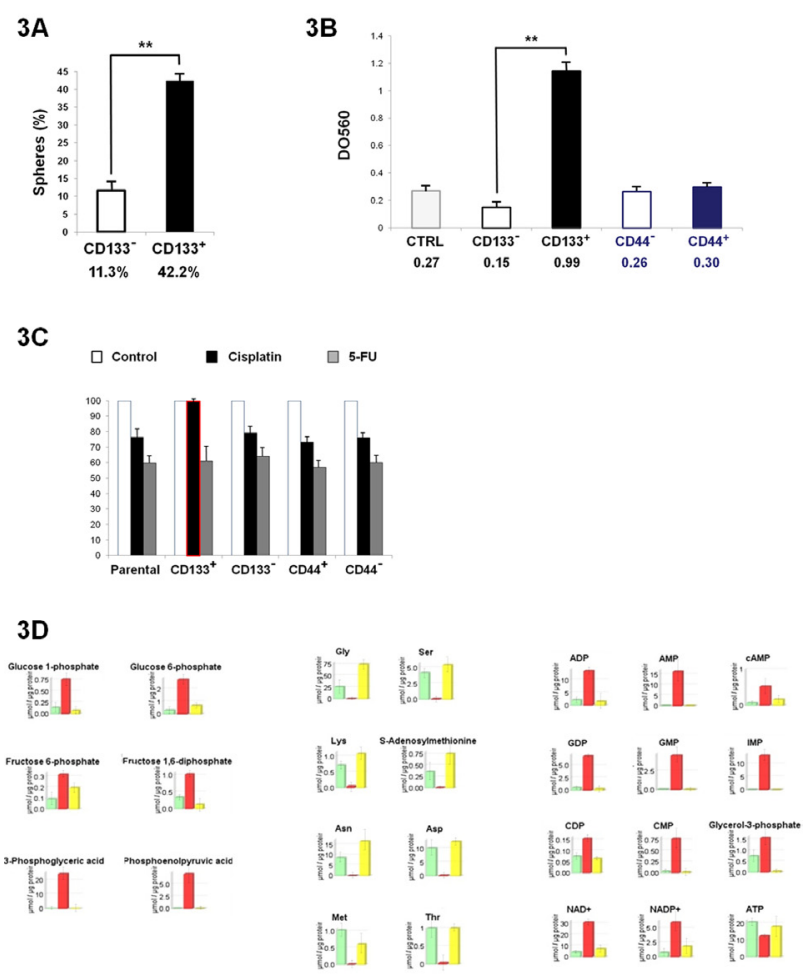

Figure 3: Colo205 CD133+ cells exhibit the phenotypic profile of CSCs. A. Tumorsphere evaluation of CD133+ and CD133- sorted cells. B. Invasiveness of different cell fractions measured using a collagen-based invasion kit (relative DO measured at $560 \mathrm{~nm}$ ). C. Survival assay after chemotherapy treatment with cisplatin and 5-FU. D. Metabolite quantification after CE-TOF-MS experiments. Only metabolites of interest for Colo205 cells cultured in 10\% FBS (control; green bar), CD133+ sorted cells (red bar) and CD44+ sorted cells (yellow bar) are reported here. 
Cells were exposed to $10 \mu \mathrm{M}$ cisplatin and 5-FU, and then analyzed for survival. The CD133+ cell population exhibited significantly increased resistance to cisplatin anti-tumor treatment, while no significant difference was observed concerning 5-FU drug treatment (Figure 3C). These findings suggested that the Colo205 CD133+ population has increased resistance to the common colon anti-cancer chemotherapeutic drug cisplatin, while other cell populations do not show any resistance to both of the investigated drugs.

\section{Colo205 CD133+ cells have specific metabolome expression.}

To identify specific metabolome features, CETOF-MS analyses were performed after cell sorting. The results showed that only the $\mathrm{CD} 133+$ purified fraction had a significantly different metabolome profile compared with the other cell fractions. No significant difference was observed for CD44+, CD44-, CD133- and parental Colo205 cells (Figure 3D). On the one hand, the $\mathrm{CD} 133+$ cell fraction exhibited high overall increases in glycogen, components of the citrate cycle, nucleotides and components of co-factor metabolism pathways (from two to ten times higher than in parental Colo205 cells). On the other hand, amino acid metabolites were barely detectable within CD133+ cells compared with those in other fractions. CE-TOF-MS analyses revealed that 28 metabolites were upregulated while 53 metabolites were downregulated in CD133-positive cells (Figure S1). These metabolome results reinforced the exclusiveness of the phenotype observed within the CD133+ cell population

$4 \mathrm{~A}$

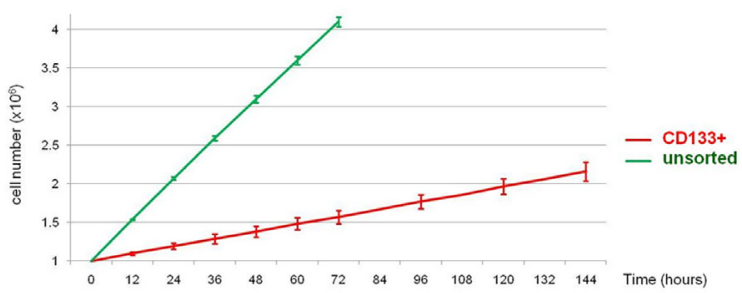

4B
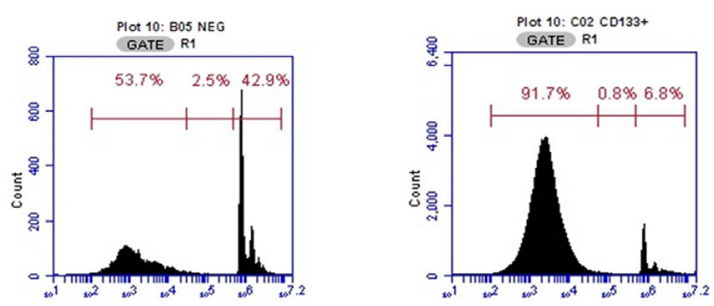

Figure 4: Growth evaluation of CD133+ cells derived from Colo205. A. Doubling time calculation of unsorted Colo205 cells vs. CD133+ sorted cells. B. Cell cycle analysis (PI staining) of Colo205 CD133- and CD133+ sorted cells. derived from the Colo205 cell line.

\section{Serum-free cultures lead to restructuring of the whole metabolome.}

As phenotypic differences had been highlighted among cultured Colo205 cells, we performed CE-TOFMS on these cells. The results indicated that serum-free culture (for three to five weeks) led to overall increases in the metabolome related to glycogenosis, glycolysis, the citrate cycle, amino acid synthesis and nucleotide metabolism pathways. Compared with the control, 78 metabolites were upregulated while only five metabolites were downregulated after five weeks in serum-free culture (Figure S2).

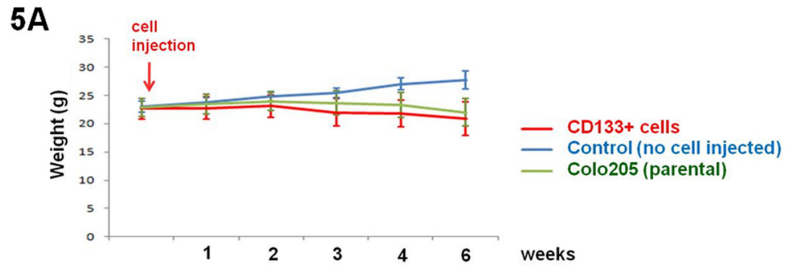

5B

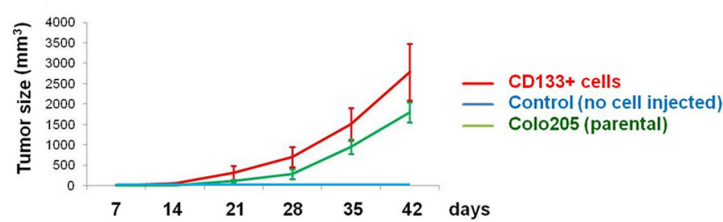

5C
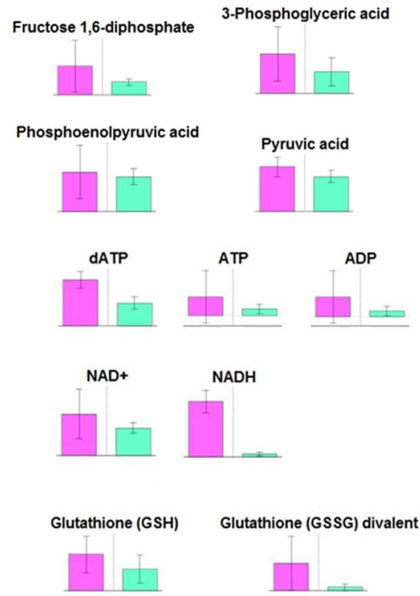

Figure 5: CD133+ cells are more tumorigenic in vivo than unsorted Colo205 cells. A. Evaluation of mouse weight after cell inoculation. B. Tumor size evaluation after inoculations of parental Colo205 cells (unsorted) and CD133+ cells in Balb/c mice. C. Metabolite quantification after CETOF-MS experiments. Metabolites were quantified from mouse serum after tumor development from Colo205 CD133+ sorted cells (purple bar) and parental unsorted Colo205 cells (green bar). Metabolites of interest reported here were quantified six weeks after s.c. inoculation. 


\section{CD133 + cells have a slow development rate in vitro.}

We investigated the growth of unsorted Colo205, CD133+ and CD133- cell fractions in basal 10\% FBS in vitro culture. While unsorted parental Colo205 cells had a population doubling time of less than $24 \mathrm{~h}(22 \pm 1.4 \mathrm{~h})$, $\mathrm{CD} 133+$ cells had a far slower development rate $(126 \pm 8.7$ h) (Figure 4A). Cell cycle analyses revealed that CD133+ cells had a decreased transition rate out of the $\mathrm{G}_{0} / \mathrm{G}_{1}$ phase into the S phase. In fact, less than $10 \%$ of CD133+ cells were in the $S$ phase $(6.9 \pm 0.7 \%)$, while most of them remained in the $\mathrm{G}_{0} / \mathrm{G}_{1}$ phase $(82 \pm 2.1 \%)$. In contrast, almost half of CD133- cells remained in the $\mathrm{G}_{0} / \mathrm{G}_{1}$ phase $(51.2 \pm 2.3 \%)$ or had started the $\mathrm{S}$ phase $(43.1 \pm 1.6 \%)$ (Figure 4B).

\section{CD133+ cells are more tumorigenic in vivo.}

To assess the in vivo tumorigenicity of CD133+ cells, various Colo205 cell fractions were injected into mice at different concentrations. $B A L B / c$ Nude mice $(\mathrm{n}=6)$ were subcutaneously (s.c.) inoculated with parental cells, or purified CD133+ or CD133- Colo205 cells. Tumor development was more efficient for $\mathrm{CD} 133+$ purified cells than for the other cell fractions (Figures 5A, 5B). While only $5 \times 10^{4} \mathrm{CD} 133+$ cells were shown to be able to expand and give rise to a complete tumor bulk after seven days (2/6), it took more than six weeks to observe formation of a single tumor bulk from $2 \times 10^{6}$ CD133purified inoculated cells (1/6) (Table S1).

As tumor growth from purified CD133+ cells was greater than from CD133- cells under identical conditions, secondary tumors were also found in a few mice inoculated with purified CD133+ cells only $(2 / 12)$, suggesting increased metastatic potential for this cell population. No metastasis was found in "CD133-negative" and "parental" inoculated mice after 10 weeks. We also observed that $30 \%$ of the mice inoculated with CD133+ purified cells suddenly died in less than five weeks (3/10), independently of tumor size. Meanwhile, in the CD133group, no mice died, even 12 weeks after s.c. inoculation (0/10; data not shown). These findings confirmed that Colo205 CD133+ cells have higher tumorigenicity than other cell populations.

\section{Tumor development of Colo205 CD133+ cells led to reorganization of metabolome expression in mice.}

Cytometry analyses were performed on each sample to confirm the selection efficiency prior to inoculation.
CD133+ purity was higher than $97 \%$ after sorting and no $\mathrm{CD} 133+$ cells were detectable in the remaining CD133cell fraction $(n=12)$. On the basis of our preliminary in vivo tumor growth development results, we chose to inject $2 \times 10^{5} \mathrm{CD} 133+$ cells, while $1 \times 10^{7}$ cells were injected in the CD133-/parental group, so we could compare metabolite variations under similar tumor growth conditions at each stage of our study. Cytometry analyses first revealed that $\mathrm{CD} 133+$ purified cells gave rise to a heterogeneous population in vivo, mainly composed of CD133- cells. In fact, six weeks after inoculation of purified CD133+ cells, only $2.6 \%$ of remaining CD133+ cells could be detected within tumor bulks $(2.6 \pm 0.7 \% ; n=6)$. On the other hand, while no CD133+ cells could be detected in the CD133- fraction prior to injection, a few CD133+ cells were then detected in tumors after six weeks $(0.29 \pm 0.15 \%$; $\mathrm{n}=6$ ). Thus, even if the CD133+ cell population was drastically reduced during the tumor development process, prominin-1 expression in tumors was still eight times higher in the CD133+ group than in tumors derived from the CD133- fraction ( $2.6 \%$ vs. $0.29 \%$, respectively; $n=6$ ) (Table S2).

\section{Metabolome analyses were performed once a week on each mouse following s.c. injection.}

Three mouse groups were thus analyzed: those with "parental" cells containing unsorted Colo205 cells, and those with "CD133+" and "CD133-" sorted populations. Despite precise CE-TOF-MS analyses ( $\mathrm{n}=90)$, only limited variation in metabolite concentrations was highlighted among the three different groups tested. Specifically, metabolome analyses revealed that only components of the glycolysis pathway, dATP, ATP, ADP, NAD+, NADH and glutathione (mono-GSH and divalent $\gamma$-GCS forms) molecules, were significantly overexpressed in the serum of mice that developed tumors from $\mathrm{CD} 133+$ purified cells compared with those in tumors derived from the CD133- population (Figure 5C). These results confirm the specific features of the CD133+ CSC population within the Colo205 adenocarcinoma cell line.

\section{DISCUSSION}

Tumor tissues have been shown to contain highly heterogeneous cell populations $[2,9,17]$. However, the role of each population and their interrelationships remain unclear and need to be determined to establish alternative effective diagnostic methods and therapeutics. Even though the existence of CSCs remains controversial, some authors have argued that new revolutionary therapeutic approaches could be achieved by focusing on stem-like cells subpopulation $[18,20]$. Indeed, CSCs were shown 
to have high clonogenicity and increased invasiveness, being able to give rise to a complete tumor bulk and to enhance metastasis, even from a few cells remaining after surgical resection [24, 25]. Moreover, these cells have been shown to be more resistant to common chemotherapy and radiotherapy treatments in many solid tumors [14, 26]. Thus, we postulate that eradicating such resistant cells could lead to a loss of clonogenicity and drastically reduce the risk of recurrence or metastasis after resection and treatment.

Previous studies have already described many markers to characterize CSCs $[1,9,17]$. Nevertheless, the presence of a universal marker for colon CSC characterization remains controversial. We demonstrated here that CD133 was the only reliable marker for phenotypic characterization of CSCs within the Colo205 cell line. In fact, the small population of CD133+ cells $(1 \%-2 \%)$ exhibited both in vitro and in vivo characteristics of CSCs, such as high clonogenicity, increased invasiveness and high expression of specific stem cell markers (i.e. MAP2, nanog, oct3/4). Moreover, we highlighted that Colo205 CD133+ cells were more resistant to the anti-tumor drug cisplatin. Our results also showed high tumorigenic and metastatic potential of the $\mathrm{CD} 133+$ population after inoculation in mice. Even though the CD44v8-10 variant form was previously shown to be related to CSCs in stomach cancer, no relationship could be clearly established between CD133 and CD44 variant populations within our Colo205 colon cancer model [9, 27]. This reinforces the apparent absence of a common universal surface marker for CSCs.

Several metabolome analyses have recently been conducted in the field of cancer research to discover new diagnostic markers or potential therapeutic targets [18, $19,23,28]$. The high resolution and sensitivity of this technique combined with molecular analyses revealed an additional powerful tool for advanced research. Our results highlighted that Colo205 CD133+ cells that harbor a stem-cell-like phenotype also have a specific metabolome profile. CD133+ cells exhibited increased expression of components related to the glycolysis pathway, the citrate cycle pathway and co-factors. Moreover, CD133+ cells exhibited a drastically increased level of nucleoside mono- and diphosphate molecules (e.g. ADP, cAMP, AMP), while other nucleotides like ATP were slightly decreased compared with those in CD133negative cells. Additionally, amino acid content almost completely disappeared in $\mathrm{CD} 133+$ cells, suggesting that protein synthesis was drastically inhibited in CSCs. Cellular differentiation has been shown to be associated with pronounced downregulation of glycolysis [14, 21, $29,30]$. Thus, overexpression of this metabolic pathway in CD133+ cells can be considered to be suggestive of the "non-proliferative" state of this population. Moreover,
acetyl-CoA, which is required for chromatin acetylation, cholesterol and glucose-dependent lipid synthesis, was completely inhibited in CD133+ cells, in contrast to that in the control. This specific metabolomic profile and the fact that most (>90\%) CD133+ cells remained in the $\mathrm{G}_{0} /$ $\mathrm{G}_{1}$ phase confirm the hypothesis supported by previous studies, namely, that CSCs have a propensity to remain in a relatively quiescent state $[31,32]$. We postulate here that the accumulation of mono- and diphosphate nucleosides associated with strong down-regulation of amino acid content could be associated with an energy-saving process. Indeed, cAMP, AMP and ADP can be easily converted to ATP via aerobic respiration in the mitochondria [33]. This "pre-ATP" stock may be a versatile energy source for amino acid synthesis, which is known as a strongly endergonic process [34]. Thus, the conditions required for entry into the $\mathrm{G}_{2} / \mathrm{S}$ phase seem to be possible if the proliferation of CD133+ cells is needed.

In our study, CD133+ cells were shown to be resistant to cisplatin. While several mechanisms of cisplatin resistance have already been described, including changes in cellular uptake and drug efflux, increased drug detoxification, inhibition of apoptosis and increased DNA repair $[26,32,35]$, we postulate here that the metabolic quiescence and slow proliferation of CD133+ cells could also provide another opportunity for CSCs to escape from antitumor chemotherapy treatments. As most CD133+ cells stay in the $\mathrm{G}_{0} / \mathrm{G}_{1}$ phase, a strained activation of all CSCs to differentiate could be an interesting potential therapy to explore, promoting the subsequent targeting of cells by chemotherapy drugs that are specifically aimed to affect cell division [36].

In vivo analyses also confirmed the existence of a specific metabolic profile when mice were inoculated with purified CD133+ cells. We reported a significant increase of components of the glycolysis pathway, glutathione molecules, NAD+/NADH and ATP in mouse serum after tumor development. Besides overexpression of GSH and $\gamma$-GSH molecules, which has been shown to enhance cisplatin resistance, a high concentration of circulating ATP and co-factors could also promote tumor cell proliferation $[32,35]$. This specific metabolome observed in mice indicated that a high concentration of CD133+ cells in a tumor might lead to a strong Warburg effect in vivo $[37,38,39]$. As an increased rate of metastasis was observed after CD133+ cell inoculation, rearrangements of the cellular micro-environment could also lead to CD133+ progenitors circulating and enhance the development of metastasis [21, 24, 40, 41, 42].

Our in vitro studies also highlighted that the metabolome profile was unnaturally elevated in tumorspheres compared with that in control cells. Almost 100 molecules were regulated in opposite ways depending on the method used for culture (i.e. 10\% FBS vs. serum- 
free) and important variations were also observed in mRNA and protein levels between CD133+ purified cells and tumorsphere-derived ones. Even though tumorsphere culture is the best way to expand and enrich CD133+ cells in vitro, we accept that the serum-free expansion protocol conventionally used for stem/progenitor cell proliferation is not reliable for use prior to CSC molecular analyses [43].

In this work, we confirmed that Colo205 tumor bulks consisted of a heterogeneous population in which two clear cell subpopulations are maintained $[44,45]$. On the one hand, there is the $\mathrm{CD} 133+$ cell population, which is a small population with clear CSC characteristics: resistance to chemotherapy, slow development rate, low metabolism, strong capacity for tumor formation, tissue invasion and metastasis formation $[3,13,26,46]$. On the other hand, the remaining CD133- cells, with a rapid proliferation cycle, could barely give rise to tumors in vivo. Despite that, accurate discrimination of the stem cell subpopulations remains a difficult process. Indeed, some CD133+ cells are barely detectable as the externalization of the CD133/prominin marker on the membrane has not yet been completed at the time of the sorting/analysis process [47]. Thus, a few cells expressing CD133/prominin but displaying a false-negative phenotype cannot be detected or isolated by conventional cytometry/sorting techniques, and might contaminate the pure CD133- cell fraction. This could explain why a few $\mathrm{CD} 133+$ cells could be detected after the development of a tumor derived from the purified CD133- population. Even though the need for collaboration between stem and non-stem cell subpopulations for efficient proliferation/ differentiation processes in different models has already been described $[17,48,49,50]$, interactions among CD133+ cells, CD133- cells and the tumor environment remain unclear [17]. If the differentiation of CD133+ cells giving rise to CD133- cells is proven, we also support the hypothesis that, in the absence of CD133+ cells, some CD133- cells might dedifferentiate and give rise to $\mathrm{CD} 133+\mathrm{CSCs}$ able to promote tumor development and metastasis. Unfortunately, given the probable rarity of this and its occurrence only under specific in vivo conditions, spontaneous dedifferentiation is assumed to be a complicated process to observe and a major challenge to identify in future studies.

\section{METHODS}

\section{Cell lines and in vitro cultures}

The Colo205 human adenocarcinoma colon cell line was obtained from the American Type Culture Collection
(ATCC). Cells were cultured in RPMI 1640 medium supplemented with $10 \%$ fetal bovine serum (FBS, Gibco). Tumorsphere formation was performed in serum-free medium supplemented with $20 \mathrm{ng} / \mathrm{mL}$ human recombinant EGF (PeproTech) and $10 \mathrm{ng} / \mathrm{mL}$ human recombinant bFGF (PeproTech).

\section{CD133+ and CD44+ cell selection}

Colo205 cells were collected using collagenase (Sigma-Aldrich) and were then fractionated using a CD133 or CD44 cell isolation kit (Miltenyi Biotec). Magnetic sorting was performed at least twice for each sample. The purity of sorted cells was evaluated by flow cytometry using FACSCalibur (BD Biosciences) after labeling with anti-human CD133/2 or CD44 antibody (Miltenyi Biotec).

\section{Immunofluorescent staining}

For intracellular staining, cells were counted, washed twice in phosphate-buffered saline (PBS, Gibco) and fixed in $\mathrm{PBS} / 3.7 \%$ formaldehyde (Sigma-Aldrich) for 20 minutes at $4^{\circ} \mathrm{C}$. The cells were then permeabilized with PBS $/ 0.1 \%$ Triton X-100 (Sigma-Aldrich) for 10 minutes at room temperature. They were subsequently washed and incubated for one hour at $4^{\circ} \mathrm{C}$ with mouse monoclonal primary antibodies: anti-nestin (MAB1259, 5 $\mu \mathrm{g} / \mathrm{mL}$; R\&D Systems), anti-CK20 (M7019, 1/200; Dako) and anti-sox2 (MAB2018, $5 \mu \mathrm{g} / \mathrm{mL}$; R\&D Systems), or with rat monoclonal primary antibody anti-oct3/4 (MAB1759, $5 \mu \mathrm{g} / \mathrm{mL}$; R\&D Systems). After several washes, cells were incubated for 30 minutes with the appropriate secondary antibody: anti-mouse antibody conjugated to fluorescein isothiocyanate (FITC) (115096-062, 1/200; Jackson Immunoresearch), PE-conjugated anti-mouse antibody (115-116-068, 1/200; Jackson Immunoresearch), rhodamine-conjugated anti-mouse antibody (115-026-003, 1/200; Jackson Immunoresearch) or FITC-conjugated anti-rat antibody (112-096-003, 1/200; Jackson Immunoresearch). For membrane staining, cells were incubated for 30 minutes at $4{ }^{\circ} \mathrm{C}$ with anti-CD133-PE (130-090-853, 1/200, Miltenyi Biotec), anti-CD44-PE (130-095-180, 1/200, Miltenyi Biotec) or primary rat monoclonal antibody anti-human $\mathrm{CD} 44 \mathrm{v} 8-10$ (ALG011, 1/1000, Link Genomics). For anti-CD44v8-10 detection, cells were further stained with secondary FITC-conjugated anti-rat antibody (112-096-003, 1/200; Jackson Immunoresearch). Nuclear DNA staining was also performed with 4',6'-diamidino-2-phenylindole (DAPI; D8417, 1/5000; Sigma-Aldrich). Cells were then washed and viewed under a fluorescent microscope. Negative controls with anti-human IgG antibodies were used to 
discard false-positive cells in the immunofluorescent staining (Jackson Immunoresearch). Aldefluor staining was also performed to quantify ALDH1-positive cells (Aldagen).

\section{Flow cytometry analysis}

To assess the sorting process of the Colo205 cell line, selected cells were stained by both relevant monoclonal antibodies: PE-conjugated AC133/2-PE antibody (130090-853, 1/200; Miltenyi Biotec) and PE-conjugated CD44-PE antibody (130-095-180, 1/200; Miltenyi Biotec), or with similarly conjugated isotype-matched antibodies, for 30 minutes at $4^{\circ} \mathrm{C}$. Cytometry analyses revealed that $95.2 \pm 2.9 \%(\mathrm{n}=19)$ of the selected cells were CD133+ after sorting, while $94.3 \pm 3.6 \%(\mathrm{n}=15)$ of the selected cells were CD44+ after sorting. Furthermore, no CD133+ or CD44+ cells could be detected within the respective remaining negative fractions (i.e. CD133- or CD44-).

\section{Reverse-transcription polymerase chain reaction (RT-PCR)}

Total RNA was isolated using Trizol Reagent (Invitrogen), according to the manufacturer's procedures. Primers were synthesized by Sigma-Aldrich. The specific oligonucleotide primers for the GAPDH gene were: TGA AGG TCG GAG TCA ACG GAT TTG G (sense) and CAT GTA GGC CAT GAG GTC CAC CAC (antisense), for the nestin gene: AGG ATG TGG AGG TAG TGA GA (sense) and TGG AGA TCT CAG TGG CTC TT (antisense), for the CD133 gene: TTA CGG CAC TCT TCA CCT (sense) and TAT TCC ACA AGC AGC AAA (antisense), for the oct4 gene: CGC ACC ACT GGC ATT GTC AT (sense) and TTC TCC TTG ATG TCA CGC AC (antisense), for the ABCG2 gene: CTG AGA TCC TGA GCC TTT GG (sense) and TGC CCA TCA CAA CAT CAT CT (antisense), for the Nanog gene: AAT ACC TCA GCC TCC AGC AGA TG (sense) and CTG CGT CAC ACC ATT GCT ATT CT (antisense), and for the hTERT gene: AGC CAG TCT CAC CTT CAA CCG C (sense) and GGA GTA GCA GAG GGA GGC CG (antisense). RNA was quantified with the Qubit RNA BR Assay Kit (Invitrogen). cDNA was synthesized using Prime Script $1^{\text {st }}$ strand cDNA Synthesis Kit (Takara Bio). The PCR reaction mixture contained $5 \mu \mathrm{L}(20 \mu \mathrm{M})$ of the above specific primers, $5 \mu \mathrm{L}$ of Taq DNA Polymerase, $16 \mu \mathrm{L}$ of $4 \times \mathrm{dNTP}, 20 \mu \mathrm{L}$ of $10 \times$ buffer, $20 \mu \mathrm{L}$ of cDNA and $133 \mu \mathrm{L}$ of $\mathrm{ddH}_{2} \mathrm{O}$. The conditions used were as follows: denaturation at $95^{\circ} \mathrm{C}$ for $5 \mathrm{~min} ; 30$ cycles of annealing at $65^{\circ} \mathrm{C}$ (for GAPDH and hTERT), $63^{\circ} \mathrm{C}$ (for oct 4 and nanog), $60^{\circ} \mathrm{C}$ (for $\mathrm{ABCG} 2$ ), $56^{\circ} \mathrm{C}$ (for nestin) or $54^{\circ} \mathrm{C}$ (for $\mathrm{CD} 133$ ) for $15 \mathrm{~s}$, and extension at $72^{\circ} \mathrm{C}$ for $1 \mathrm{~min}$; and then heating at $72^{\circ} \mathrm{C}$ for $7 \mathrm{~min}$. The PCR products were resolved on a $2 \%$ agarose gel containing fluorescent nucleic acid gel stain GelRed ${ }^{\mathrm{TM}}$ (Biotium). Acquisition of gel pictures and quantification were then performed with ImageQuant TL 7.0 (GE Healthcare).

\section{Colony formation assay}

Colony formation assay was performed in soft agar. A base layer was prepared by mixing $1 \%$ soft agar (Invitrogen) in the medium. Then, cells were suspended in growth medium containing $0.3 \%$ soft agar and seeded upon the base layer at a density of 2500 cells per well. All experiments were conducted at least in triplicate. Plates were maintained at $37^{\circ} \mathrm{C}$ in a humidified $5 \% \mathrm{CO}_{2}$ incubator and medium was added every three days. After three weeks, colonies ( $>10$ cells) were counted under a microscope.

\section{Cell invasion assay}

QCM Collagen-based Cell Invasion Assay Kit (Chemicon, Millipore) was used following the manufacturer's procedures. Cells were seeded into the upper insert at $1 \times 10^{5}$ cells per insert in serum-free medium. Outer wells were filled with RPMI medium containing $10 \% \mathrm{FBS}$ as a chemoattractant. Cells were then incubated for 48 hours. Non-invading cells were removed by swabbing the top layer of collagen and cells able to migrate through the gel insert to the lower surface of the membrane were stained, solubilized and quantified by colorimetric measurements at $560 \mathrm{~nm}$ (Glomax Multidetector System, Promega). All experiments were conducted in triplicate.

\section{In vitro drug sensitivity assays}

Drug sensitivity was evaluated using cisplatin and 5-fluorouracil (5-FU) (Sigma-Aldrich). In accordance with the manufacturer's instructions, cells were exposed to 10 $\mu \mathrm{M}$ cisplatin or $10 \mu \mathrm{M} 5$-FU for $72 \mathrm{~h}$. Viability was then evaluated using the CellTiter 96 AQueous proliferation assay kit, by measuring absorbance at $490 \mathrm{~nm}$ (Promega). Experiments were conducted in triplicate for each sample.

\section{Doubling time calculation}

Cells were plated at $10^{5}$ cells/well in six-well plates and manually counted with a hemocytometer. Doubling time (Td) was calculated using the following equation: $\mathrm{Td}=(\mathrm{t} 2-\mathrm{t} 1) \times \log (2) / \log (\mathrm{q} 1 / \mathrm{q} 2)$, where $\mathrm{q} 1$ and $\mathrm{q} 2$ represent the numbers of cells at times $\mathrm{t} 1$ and $\mathrm{t} 2$, respectively $(\mathrm{n}=6)$. 


\section{Cell cycle analysis}

The cell cycle was evaluated by cytometry using propidium iodide (PI) solution (Sigma-Aldrich). After fixation in $70 \%$ ethanol solution, cells were washed twice in PBS and stained using $250 \mu \mathrm{l}$ of RNase solution $(2 \mathrm{mg} /$ $\mathrm{ml}$, Sigma-Aldrich) added to $250 \mu \mathrm{l}$ of PI solution (0.1 $\mathrm{mg} / \mathrm{ml}$ in $0.6 \%$ Triton-X in PBS) for 45 minutes in the dark at room temperature. Cells were then transferred through capped tubes to avoid clumps during fluorescence detection. Samples were kept on ice and protected from light until cytometry analysis (Accuri C6, BD Biosciences).

\section{In vivo analyses}

Male BALB/c mice (all six weeks of age) were obtained from the National Cancer Institute (Frederick, MD, USA). The mice were subcutaneously (s.c.) injected with $1 \times 10^{7}$ Colo205 cells. CD133+ and CD133- cells were also injected after sorting $\left(5 \times 10^{4}\right.$ to $2 \times 10^{6}$ cells $)$. At specified times after tumor inoculation, the mice were euthanized in a $\mathrm{CO}_{2}$ chamber and tumor cell suspensions were prepared from solid tumors by enzymatic digestion as follows. Minced tissues $\left(<1 \mathrm{~mm}^{3}\right)$ from tumors were incubated at $37^{\circ} \mathrm{C}$ for 90 minutes in standard medium containing $2 \%$ FBS, $50 \mathrm{U} / \mathrm{ml}$ collagenase I, $100 \mathrm{U} /$ $\mathrm{ml}$ collagenase IV, $200 \mathrm{U} / \mathrm{ml}$ DNase-I and $2.5 \mathrm{U} / \mathrm{ml}$ protease XIV. Cells were then harvested for viability and immunocytometry characterization.

\section{Capillary electrophoresis-time of flight-mass spectrometry analyses (CE-TOF-MS)}

Metabolite standards, instrumentation and CETOF-MS conditions. Instrumentation and CE-TOF-MS conditions followed the Human Metabolome Technologies guidelines (HMT Inc.). CE-TOF-MS experiments were performed on an Agilent capillary electrophoresis system coupled to an Agilent $6224 \mathrm{CE} / \mathrm{TOF}-\mathrm{MS}$ analyzer (Agilent Technologies). System control and data acquisition were processed using the Agilent Chemstation software.

CE-TOF-MS was conducted in both positive and negative ion modes for each sample. Molecule separation was processed in fused-silica capillaries filled with $1 \mathrm{M}$ formic acid as a background electrolyte. Samples were injected at $50 \mathrm{mbar}$, and a voltage of $27 \mathrm{kV}$ (for cation mode) or $30 \mathrm{kV}$ (for anion mode) was applied. Capillary temperature was maintained at $20^{\circ} \mathrm{C}$ while sample tray temperature was kept below $10^{\circ} \mathrm{C}$. Sheath liquid was delivered at $10 \mu \mathrm{L} / \mathrm{min}$. Capillary voltage was set at $4 \mathrm{kV}$ for cation mode and $3.5 \mathrm{kV}$ for anion mode; the flow rate of nitrogen gas (heater temperature $300^{\circ} \mathrm{C}$ ) was set at 0.35 bar. Fragmentor, skimmer and Oct RFV voltages were set according to HMT setting recommendations (HMT Inc.). Exact mass data were acquired at a rate of 1.5 cycles per second over the range of $50-1000 \mathrm{~m} / \mathrm{z}$.

\section{Processing of CE-TOF-MS data}

Raw data were extracted with MassHunter software (Agilent Technologies). Data processing was then performed using MasterHands software developed by HMT (MasterHands v2.8.0.3, HMT Inc.). Data analysis included noise-filtering, baseline correction, peak detection and integration of the peak area from sliced electropherograms (width $0.02 \mathrm{~m} / \mathrm{z}$ ). Alignment was carried out and accurate $m / z$ values were determined for each detected peak. All peak areas were then quantified by comparison to the values of internal standard molecules (relative area) to normalize signal intensities among multiple measurements. Undetected peaks with a threshold signal-to-noise ratio of 2 were given a peak area of 0 and then discarded.

\section{Metabolite identification}

To discriminate metabolites of interest, peak identification was carried out based on matched $\mathrm{m} / \mathrm{z}$ values and normalized migration times of standard compounds (standard mixtures H3301-10024, HMT Inc.). After alignment, all data were processed with MasterHands software to confirm and refine the surface of each peak according to the $\mathrm{m} / \mathrm{z}$ values.

\section{Mapping process}

Statistical analysis was carried out by calculating mean error and standard deviation for each group. Results were finally processed with Vanted software (V1.9) to create metabolic pathway mapping, including all metabolites of interest.

\section{REFERENCES}

1. Charafe-Jauffret E, Ginestier C, Bertucci F, Cabaud O, Wicinski J, Finetti P, Josselin E, Adelaide J, Nguyen TT, Monville F, Jacquemier J, Thomassin-Piana J, Pinna G, et al. ALDH1-positive cancer stem cells predict engraftment of primary breast tumors and are governed by a common stem cell program. Cancer Res. 2013; 73(24): 7290-7300.

2. Yin S, Li J, Hu C, Chen X, Yao M, Yan M, Jiang G, Ge C, Xie H, Wan D, Yang S, Zheng S, Gu J. CD133 positive hepatocellular carcinoma cells possess high capacity for tumorigenicity. Int J Cancer. 2007; 120(7): 1444-1450. 
3. O'Brien CA, Pollett A, Gallinger S, Dick JE. A human colon cancer cell capable of initiating tumour growth in immunodeficient mice. Nature. 2007; 445(7123): 106-110.

4. Yae T, Tsuchihashi K, Ishimoto T, Motohara T, Yoshikawa M, Yoshida GJ, Wada T, Masuko T, Mogushi K, Tanaka H, Osawa T, Kanki Y, Minami T, et al. Alternative splicing of CD44 mRNA by ESRP1 enhances lung colonization of metastatic cancer cell. Nat Commun. 2012; 3: 883.

5. Ricci-Vitiani L, Lombardi DG, Pilozzi E, Biffoni M, Todaro M, Peschle C, De Maria R. Identification and expansion of human colon-cancer-initiating cells. Nature. 2007; 445(7123): 111-115.

6. Qiang L, Yang Y, Ma YJ, Chen FH, Zhang LB, Liu W, Qi Q, Lu N, Tao L, Wang XT, You QD, Guo QL. Isolation and characterization of cancer stem like cells in human glioblastoma cell lines. Cancer Lett. 2009; 279(1): 13-21.

7. Liu H, Patel MR, Prescher JA, Patsialou A, Qian D, Lin J, Wen S, Chang YF, Bachmann MH, Shimono Y, Dalerba P, Adorno M, Lobo N, et al. Cancer stem cells from human breast tumors are involved in spontaneous metastases in orthotopic mouse models. Proc Natl Acad Sci USA. 2010; 107(42): 18115-18120.

8. Christ O, Lucke K, Imren S, Leung K, Hamilton M, Eaves A, Smith C, Eaves C. Improved purification of hematopoietic stem cells based on their elevated aldehyde dehydrogenase activity. Haematologica. 2007; 92(9): 11651172.

9. Bensimon J, Altmeyer-Morel S, Benjelloun H, Chevillard S, Lebeau J. CD24(-/low) stem-like breast cancer marker defines the radiation-resistant cells involved in memorization and transmission of radiation-induced genomic instability. Oncogene. 2013; 32(2): 251-258.

10. Huang EH, Hynes MJ, Zhang T, Ginestier C, Dontu G, Appelman H, Fields JZ, Wicha MS, Boman BM. Aldehyde dehydrogenase 1 is a marker for normal and malignant human colonic stem cells (SC) and tracks SC overpopulation during colon tumorigenesis. Cancer Res. 2009; 69(8): 3382-3389.

11. Jung P, Sato T, Merlos-Suárez A, Barriga FM, Iglesias M, Rossell D, Auer H, Gallardo M, Blasco MA, Sancho $\mathrm{E}$, Clevers H, Batlle E. Isolation and in vitro expansion of human colonic stem cells. Nat Med. 2011; 17(10): 12251227.

12. Boegl M, Prinz C. CD133 expression in different stages of gastric adenocarcinoma. Br J Cancer. 2009; 100(8): 13651366.

13. Li CY, Li BX, Liang Y, Peng RQ, Ding Y, Xu DZ, Zhang X, Pan ZZ, Wan DS, Zeng YX, Zhu XF, Zhang XS. Higher percentage of $\mathrm{CD} 133+$ cells is associated with poor prognosis in colon carcinoma patients with stage IIIB. J Transl Med. 2009; 7: 56.

14. Zhang Q, Shi S, Yen Y, Brown J, Ta JQ, Le AD. A subpopulation of $\mathrm{CD} 133(+)$ cancer stem-like cells characterized in human oral squamous cell carcinoma confer resistance to chemotherapy. Cancer Lett. 2010; 289(2): 151-160.

15. Carpentino JE, Hynes MJ, Appelman HD, Zheng T, Steindler DA, Scott EW, Huang EH. Aldehyde dehydrogenase-expressing colon stem cells contribute to tumorigenesis in the transition from colitis to cancer. Cancer Res. 2009; 69(20): 8208-8215.

16. Armstrong L, Stojkovic M, Dimmick I, Ahmad S, Stojkovic P, Hole N, Lako M. Phenotypic characterization of murine primitive hematopoietic progenitor cells isolated on basis of aldehyde dehydrogenase activity. Stem Cells. 2004; 22(7): 1142-1151.

17. Shmelkov SV, Meeus S, Moussazadeh N, Kermani P, Rashbaum WK, Rabbany SY, Hanson MA, Lane WJ, St Clair R, Walsh KA, Dias S, Jacobson JT, Hempstead BL, et al. CD133 expression is not restricted to stem cells, and both CD133+ and CD133- metastatic colon cancer cells initiate tumors. J Clin Invest. 2008; 118(6): 2111-2120.

18. Charafe-Jauffret E, Ginestier C, Birnbaum D. Breast cancer stem cells: tools and models to rely on. BMC Cancer. 2009; 9: 202.

19. Ma Y, Liu W, Peng J, Huang L, Zhang P, Zhao X, Cheng Y, Qin H. A pilot study of gas chromatograph/mass spectrometry-based serum metabolic profiling of colorectal cancer after operation. Mol Biol Rep. 2010; 37(3): 14031411.

20. Zhao Y, Butler EB, Tan M. Targeting cellular metabolism to improve cancer therapeutics. Cell Death Dis. 2013; 4: 532.

21. McGraw TE, Mittal V. Stem cells: Metabolism regulates differentiation. Nat Chem Biol. 2010; 6(3): 176-177.

22. Qiu Y, Cai G, Su M, Chen T, Zheng X, Xu Y, Ni Y, Zhao A, $\mathrm{Xu}$ LX, Cai S, Jia W. Serum metabolite profiling of human colorectal cancer using GC-TOFMS and UPLC-QTOFMS. J Proteome Res. 2009; 8(10): 4844-4850.

23. Zenobi R. Single-cell metabolomics: analytical and biological perspectives. Science. 2013; 342(6163): 1243259 .

24. Zhang LZ, Zhang CQ, Yan ZY, Yang QC, Jiang Y, Zeng BF. Tumor-initiating cells and tumor vascularization. Pediatr Blood Cancer. 2011; 56(3): 335-340.

25. Sun Y, Campisi J, Higano C, Beer TM, Porter P, Coleman I, True L, Nelson PS. Treatment-induced damage to the tumor microenvironment promotes prostate cancer therapy resistance through WNT16B. Nat Med. 2012; 18(9): 13591368.

26. Ong CW, Kim LG, Kong HH, Low LY, Iacopetta B, Soong R, Salto-Tellez M. CD133 expression predicts for nonresponse to chemotherapy in colorectal cancer. Mod Pathol. 2010; 23(3): 450-457.

27. Ishimoto $T$, Nagano $\mathrm{O}$, Yae $\mathrm{T}$, Tamada M, Motohara $\mathrm{T}$, Oshima H, Oshima M, Ikeda T, Asaba R, Yagi H, Masuko 
T, Shimizu T, Ishikawa T, et al. CD44 variant regulates redox status in cancer cells by stabilizing the $\mathrm{xCT}$ subunit of system xc(-) and thereby promotes tumor growth. Cancer Cell. 2011; 19(3): 387-400.

28. Urakami K, Zangiacomi V, Yamaguchi K, Kusuhara M. Quantitative metabolome profiling of Illicium anisatum by capillary electrophoresis time-of-flight mass spectrometry. Biomed Res. 2010; 31(2): 161-163.

29. Chen J, Li Y, Yu TS, McKay RM, Burns DK, Kernie SG, Parada LF. A restricted cell population propagates glioblastoma growth after chemotherapy. Nature. 2012; 488(7412): 522-526.

30. Vander Heiden MG, Locasale JW, Swanson KD, Sharfi H, Heffron GJ, Amador-Noguez D, Christofk HR, Wagner G, Rabinowitz JD, Asara JM, Cantley LC. Evidence for an alternative glycolytic pathway in rapidly proliferating cells. Science. 2010; 329(5998): 1492-1499.

31. Ishimoto T, Oshima H, Oshima M, Kai K, Torii R, Masuko T, Baba H, Saya H, Nagano O. CD44+ slow-cycling tumor cell expansion is triggered by cooperative actions of Wnt and prostaglandin E2 in gastric tumorigenesis. Cancer Sci. 2010; 101(3): 673-678.

32. Chen HH, Kuo MT. Role of glutathione in the regulation of cisplatin resistance in cancer chemotherapy. Met Based Drugs. 2010; 2010

33. Walker JE. The ATP synthase: the understood, the uncertain and the unknown. Biochem Soc Trans. 2013; 41(1): 1-16.

34. Maldonado EN, Lemasters JJ. Warburg revisited: regulation of mitochondrial metabolism by voltage-dependent anion channels in cancer cells. J Pharmacol Exp Ther. 2012; 342(3): 637-641.

35. Johnston PG, Geoffrey F, Drake J, Voeller D, Grem JL, Allegra CJ. The cellular interaction of 5-fluorouracil and cisplatin in a human colon carcinoma cell line. Eur $\mathrm{J}$ Cancer. 1996; 32A(12): 2148-2154.

36. Kreso A, van Galen P, Pedley NM, Lima-Fernandes E, Frelin C, Davis T, Cao L, Baiazitov R, Du W, Sydorenko N, Moon YC, Gibson L, Wang Y, et al. Self-renewal as a therapeutic target in human colorectal cancer. Nat Med. 2014; 20(1): 29-36.

37. Paldino E, Tesori V, Casalbore P, Gasbarrini A, Puglisi MA. Tumor initiating cells and chemoresistance: which is the best strategy to target colon cancer stem cells? Biomed Res Int. 2014; 2014: 859871.

38. Hitosugi T, Kang S, Vander Heiden MG, Chung TW, Elf S, Lythgoe K, Dong S, Lonial S, Wang X, Chen GZ, Xie J, Gu TL, Polakiewicz RD, et al. Tyrosine phosphorylation inhibits PKM2 to promote the Warburg effect and tumor growth. Sci Signal. 2009; 2(97): 73.

39. Kee HJ, Cheong JH. Tumor bioenergetics: an emerging avenue for cancer metabolism targeted therapy. BMB Rep. 2014; 47(3): 158-166.

40. Liu Y, Han ZP, Zhang SS, Jing YY, Bu XX, Wang CY, Sun $\mathrm{K}$, Jiang GC, Zhao X, Li R, Gao L, Zhao QD, Wu MC, et al. Effects of inflammatory factors on mesenchymal stem cells and their role in the promotion of tumor angiogenesis in colon cancer. J Biol Chem. 2011; 286(28): 25007-25015.

41. Kincade PW. Plasticity of supporting cells in a stem cell factory. Immunity. 2010; 33(3): 291-293.

42. Hirayama A, Kami K, Sugimoto M, Sugawara M, Toki N, Onozuka H, Kinoshita T, Saito N, Ochiai A, Tomita M, Esumi H, Soga T. Quantitative metabolome profiling of colon and stomach cancer microenvironment by capillary electrophoresis time-of-flight mass spectrometry. Cancer Res. 2009; 69(11): 4918-4925.

43. Hartmann M, Zimmermann D, Nolte J. Changes of the metabolism of the colon cancer cell line SW-480 under serum-free and serum-reduced growth conditions. In Vitro Cell Dev Biol Anim. 2008; 44(10): 458-463.

44. Magee JA, Piskounova E, Morrison SJ. Cancer stem cells: impact, heterogeneity, and uncertainty. Cancer Cell. 2012; 21(3): 283-2 96.

45. Sugihara E, Saya H. Complexity of cancer stem cells. Int J Cancer. 2013; 132(6): 1249-1259.

46. Yu JW, Zhang P, Wu JG, Wu SH, Li XQ, Wang ST, Lu RQ, Ni XC, Jiang BJ. Expressions and clinical significances of CD133 protein and CD133 mRNA in primary lesion of gastric adenocarcinoma. J Exp Clin Cancer Res. 2010; 29: 141.

47. Kemper K, Sprick MR, de Bree M, Scopelliti A, Vermeulen L, Hoek M, Zeilstra J, Pals ST, Mehmet H, Stassi G, Medema JP. The AC133 epitope, but not the CD133 protein, is lost upon cancer stem cell differentiation. Cancer Res. 2010; 70(2): 719-729.

48. Zangiacomi V, Balon N, Maddens S, Lapierre V, Tiberghien P, Schlichter R, Versaux-Botteri C, Deschaseaux F. Cord blood-derived neurons are originated from CD133+/CD34 stem/progenitor cells in a cell-to-cell contact dependent manner. Stem Cells Dev. 2008; 17(5): 1005-1016.

49. Beier CP, Beier D. CD133 negative cancer stem cells in glioblastoma. Front Biosci. 2011; 3: 701-710.

50. Sampetrean O, Saya H. Characteristics of glioma stem cells. Brain Tumor Pathol. 2013; 30(4): 209-214. 